\title{
A Brief Discussion on the Classroom Teaching of University Calculus
}

\author{
Jianping Huang \\ School of mathematics and information engineering Taizhou University \\ China Zhejiang Linhai 317000 \\ 541920436@qq.com
}

\section{Keywords: Calculus; Classroom teaching; The teaching reform}

\begin{abstract}
The quality of calculus teaching directly affects the learning of College Students' professional courses. Under the background of the highly developed information age of the Internet, the author has conducted an empirical study of calculus teaching in combination with his own teaching experience, and puts forward constructive suggestions and suggestions aimed at the existing problems of calculus classroom teaching. It provides a train of thought and reference for calculus teaching reform[2].

Calculus is an important professional basic course for the freshmen to enter the university campus. This course not only takes into account the scientific nature of the higher mathematics, but also aims at the acceptance and understanding of each major students, and tries to cover the syllabus, easy to learn and practical. In accordance with the guiding ideology of "basic theory, application as the purpose and necessary enough for degree", through the teaching of higher mathematics, students not only master the basic knowledge and basic theory of higher mathematics, but also have more skilled operation skills, and can use the methods and principles of mathematical analysis to solve practical problems[1].

Because of the incomprehensible characteristics of the calculus itself, and the dull instillation type of classroom teaching, it makes most of the students feel that calculus is a boring subject, so it is difficult to form an upward trend. The motivation of learning. Therefore, how to make calculus teaching interesting and vivid is very important.

We all know that interest is the best teacher. If you have interest in doing a thing, you will be happy to do it, even if it is boring for outsiders. How can we get students interested in calculus? The teaching method of teachers is very important. Now I summarize the following experience based on my own experience.
\end{abstract}

First, we must lay down our teacher's shelf and make friends with students. Only by drawing close distance between teachers and students is it easier to get through the obstacles of communication. Because the communication between friends is more likely to establish mutual trust, once the trust is established, knowledge will unknowingly be absorbed in a relaxed and comfortable atmosphere.

Second, teaching knowledge should create a classroom atmosphere. The teacher said to himself on the stage, the effect is generally not good. Because the classroom atmosphere is created by teachers and students. We can't turn calculus classroom into "one man's craziness, a group of people's loneliness". Teachers should strengthen interaction with students, activate the classroom atmosphere by tone lifting or language setbacks or even body movements. Using this atmosphere, people who don't want to learn can also enter into a learning state involuntarily, and achieve the goal of teaching and learning imperceptibly.

Third, language organization is also important in teaching process. Teachers should not be so easy to echo what the books say, students lose interest in lectures. The organization of language in class should be an important part of preparing lessons for teachers. Choose which way to express, choose according to specific knowledge content, try to make language expression concise and clear, clear thinking.

Fourth, we should try to link knowledge points to what students are interested in. This is also an effective way to attract students' attention. In this way, there is a common language between 
teachers and students. Teachers, based on their more rich life experience, combine the knowledge points organically in every daily common sense and let the students feel a clear feeling, which shows that the teaching is successful.

Fifth, connect calculus knowledge with students' majors. In this way, it is very useful for students to really understand mathematics. The primary task for college students to go to college is to make their specialties solid. Because there is a place to settle down after graduation. Teachers should fully excavate the links between the calculus and their major, and skillfully interspersed in the classroom teaching, so that students can be better and more firmly grasps the knowledge. It is like a string of beads. If there is no string to string them together, they are isolated individuals with a rope to connect them to a whole. And the teacher is actually the role of a rope.

Sixth, In the design of teaching plan, we strive to reflect the principle of "necessary and sufficient", to weaken the system and tightness, to strengthen the practice link and to apply the concept of modern technology. The so-called desalination of systematic nature is not to emphasize the coherence and cohesion of the teaching content; the so-called desalination tightness is aimed at the weakness of the students' abstract ability, and does not pursue a strict description of the sentence by word; the emphasis on thinking is to pay attention to the way of thinking of mathematics and to embody the maintenance of mathematical quality.

Seventh, Some opening examples or instances are compiled for the theory to be taught. The explanation and summary of the examples can be summed up into the theory, and the multimedia and mathematical software can be demonstrated when necessary; the proof can be proved by the students and the proof process is proved, otherwise the process of proof is omitted; the students practise the new practice for the theory, and the students practice the teacher's explanation; the summary of this section is raised to the next section. New knowledge to be learnt; homework assignment for important exercises.

Eighth, through the establishment of class QQ group, students can discuss the questions of the course. Teachers can also timely understand the degree of students' knowledge and correct the students' Misunderstandings in time. Through the interaction between teachers and students after class, they can not only improve students' learning initiative, but also cultivate students' interest in learning.

Ninth, teachers can share the cases of actual production and life related to the curriculum to students at any time through QQ group, and then cultivate students' awareness of the application of mathematical knowledge.

Tenth, the examination should not only examine the students' mastery of the basic knowledge of mathematics, but also examine the ability of students to solve practical problems with mathematical knowledge. The examination methods should be diversified. On the one hand, we can use the form of closed volume to examine the students' mastery of mathematical knowledge; on the other hand, after the students can finish a chapter, they can arrange some mathematical application problems related to the economic profession by the teachers, let the students carry out the group discussion and cooperate to complete, and finally form a small essay or a mathematical report. The model not only examines the students' understanding and mastery of mathematical knowledge, but also raises the students' ability to analyze and solve practical problems, and also raises the students' creative ability.

Eleventh, the introduction of mathematical software as a teaching aid, so that the traditional boring and abstract classroom mode becomes lively and dynamic. Besides expressing in static way, such as character and sign language, mathematical concepts need to be moved. With the advantage of visualization in mathematical software, it provides students with an interactive and dynamic experience. Such as the definition of "epsilon $n$ " of the limit, by introducing the different values of epsilon, the corresponding figures are made by mathematical software when an example is introduced, and the students are given perceptual knowledge from the dynamic demonstration, and then the rules are summed up and the definition of the limit is summed up. In addition, the use of "element method" for area and volume can make students have a sense of approximation by the software mapping function, and better understand the relationship between the limit and the integral 
from the combination of numbers and shapes. Common mathematical softwares, such as Matlab, Mathematica, Maple, MathCAD, and Geometer's Sketchpad, can both draw mathematical figures and complete numeric symbols ${ }^{[3]}$.

Twelfth, the teaching content is processed, the practical application is highlighted, the students' consciousness of mathematical application is strengthened, and the ability of applying mathematics knowledge to solve practical problems is improved. Teachers should adjust the teaching progress, teaching methods and teaching strategies flexibly according to the different students' professional needs, so as to integrate the professional knowledge into the teaching content as much as possible. It is impossible to make an abstract proof of the mathematical theorem, and should not overemphasize the technique of solving the problem. The emphasis should be on how to apply the mathematical knowledge to the specialty, which can not only arouse the students' enthusiasm for learning, but also cultivate the students' ability to solve practical problems in Mathematics.

Thirteenth, integrate the idea of mathematical modeling into classroom teaching and cultivate the ability to solve practical problems by using mathematical knowledge. Especially for the application cases with professional background, we should follow the questions, analyze the problems, solve the problems, and let the students truly realize the practical application of mathematics, so as to change the useless theory of mathematics before. In this way, not only did we learn to use mathematics, but also improved our professional skills and attainments.

Fourteenth, students' learning styles should be diversified. At present, the learning methods of calculus in Colleges and universities are very single, in addition to classroom listening, that is to do after class, which is essentially a kind of imitation, which leads to a considerable number of students only to memorize and use their knowledge to solve practical problems in life. Contemporary constructivism holds that "textbook knowledge is only a more reliable hypothesis about all kinds of phenomena, not a" template "to explain reality, but learning is" the process of building their own knowledge ". It is not a simple input, storage and extraction of information. It should be" assimilation and adaptation ", that is, understanding and memory. New knowledge forms its own thinking on the basis of analysis, and transforms the existing knowledge and experience on the one hand. Therefore, calculus teaching must arouse students' subjective initiative and make them the main body of learning. For some unintelligible concepts and theorems, common learning methods, such as research learning, problem based learning and cooperative learning, can be adopted to strengthen communication and communication, give full play to team advantages, fully mobilize the enthusiasm of learning and complete knowledge construction. Based on the problem, students are allowed to explore, cooperate and discuss, and teachers guide them appropriately, so as to better help students understand the limitless ideas contained in the limit ${ }^{[4]}$.

Fifteenth, teachers need to improve their academic prestige and personal charisma and form their own teaching styles. A teacher with academic status can make students admire and take you as an authority in the heart. A charming teacher is more likely to move students, so that students are more willing to follow you to overcome one and one learning obstacles. These are invisible internal driving forces, which are not known much better than coercion.

Teachers are not only knowledge Porter, should be more knowledge processors. Anyone who knows fish is better than fish, which is understood by everyone. This requires teachers to explore in a large number of teaching practices, constantly thinking, and constantly summing up, and finally can get a relatively more effective teaching methods.

\section{Acknowledgements}

Project supported by Funding for the teaching reform project of Taizhou University: Research on the reform of higher mathematics teaching mode in economics and management under the background of application and by fostering fund foundation of Taizhou University. (No. 2016PY016) 


\section{Reference}

[1] Jianping Huang. O2O Model of Higher Mathematics Teaching in Local Colleges [J]. Advances in Intelligent Systems Research, 2016 (135): 204-206.

[2] YANG Hong-lin, DING Zhan-wen, TIAN Li-xin. Some Thoughts on Teaching Reform of Higher Mathematics Course[J]. Journal of Mathematics Education, 2004 , 13 (2) :74-76

[3] LI Mei-hua. Let the calculus classroom "live"[J]. XUEYUAN. 2015 NO.27:121-122.

[4] Xu Yujie, Zhang Xijuan, Liu Zhigang, Ren Zheng. Thinking of the teaching content of the professional calculus in the management[J]. EDUCATION TEACHING FORUM. Aug.2015 NO.31:199-200 